\title{
Las medidas cautelares innominadas y el activismo judicial"
}

\author{
Martha Consuelo Suárez Gómez" \\ Carlos Eduardo Vallejo Ramírez"
}

Recibido: 30 de agosto de 2016 • Aprobado: 5 de octubre de 2016

\section{Resumen}

Por medio de la investigación que fundamente este artículo obtuvimos como resultados que las medidas cautelares innominadas fortalecen el activismo judicial en la medida en que el operador judicial no sobrepase los límites legales y dichas medidas sean decretadas con proporcionalidad para garantizar el debido proceso de las partes dentro de los diferentes procesos en contienda. Como es un instrumento a disposición del juez, que lo que busca es la justicia, este debe tener gran cuidado en su implementación y establecer límites claros para que no se convierta en una decisión arbitraria y con esto, injusta. (Ragone 2015)

Estas medidas cautelares no son taxativas, sin embargo, se le confiere al juez facultades para que a solicitud de la parte interesada, las decrete; pero dicha decisión la debe forjar si las medidas solicitadas son conducentes, pertinentes y procedimentales, y de esta manera la sentencia será estimatoria.

* El presente artículo es producto de la investigación "Las medidas cautelares innominadas y el activismo judicial", la cual permitió obtener el título de especialista en Derecho Administrativo en la Universidad Libre de Colombia (sede Bogotá). DOI: http://dx.doi.org/10.15332/s19000448.2017.0046.06

"'Abogada de la Universidad La Gran Colombia, Bogotá,D.C. (Colombia). Especialista en Derecho Procesal (Universidad Libre de Colombia). Correo electrónico: martha.suarez.gomez@hotmail.com

-”- Abogado de la Universidad Universitaria de Colombia.Correo electrónico: abogadovallejocevr@ hotmail.com 
Mediante la implementación de dichas cautelas, se busca dar una solución ágil y eficaz a todas las obligaciones para hacerlas efectivas y que requieran de la comparecencia del Estado por medio de sus operadores judiciales.

Palabras clave: medida cautelar, innominada, activismo judicial, proceso.

\title{
The UNNAMED INTERIM RELIEF AND THE JUDICIAL ACTIVISM
}

\begin{abstract}
Through this article, we obtained as a result, that precautionary measures innominate strengthen judicial activism to the extent that the judicial operator does not exceed the legal limits and such measures are enacted with proportionality to ensure due process of the parties within the different processes in contention. As an instrument, available to the judge who is seeking justice, it must take great care in its implementation and set clear limits to not become an arbitrary decision and this unfair.

These precautionary measures are not exhaustive, but it gives the court power to it at the request of the party concerned, the decree, but that decision must be forged if the measures requested are conducive, relevant and procedural and thus the sentence it will be estimatory.

Through the implementation of these safeguards seeks to give a quick and effective solution to all obligations to make them effective and require the attendance of the state through its judicial operators.
\end{abstract}

Keywords: Precautionary measure, innominate, judicial activism, process.

\section{AS MEDIDAS CAUTELARES INOMINADAS E O ATIVISMO JUDICIAL}

\section{Resumo}

Por meio da pesquisa que fundamenta este artigo obteve-se como resultados que as medidas cautelares inominadas fortalecem o ativismo judicial na medida em que o operador judicial não ultrapasse os limites legais e estas medidas sejam decretadas com proporcionalidade para garantir o devido processo das partes dentro dos diferentes processos em contenda. Como é um instrumento a disposição do juiz, que procura justiça, este deve tomar cuidado com sua implementação e estabelecer 
limites claros para que não se transforme em uma decisão arbitrária e por isso injusta. (Ragone 2015)

Estas medidas cautelares não são taxativas, porém, confere-se ao juiz faculdades para que a solicitude da parte interessada as decrete; mas essa decisão as deve forjar se as medidas solicitadas são conducentes, pertinentes e processuais e de essa maneira a sentença será estimativa.

Mediante a implementação destas cautelas busca-se oferecer uma solução ágil e eficaz a todas as obrigações para fazê-las efetivas e que requeiram da comparecência do Estado por médio de seus operadores judiciais.

Palavras-chave: Medida cautelar, inominada, ativismo judicial, processo.

\section{Introducción}

Hoy por hoy, se han venido desarrollando diferentes y novedosas conceptualizaciones alrededor del derecho, en particular medida, en lo que concierne al énfasis de su papel e impacto con las estructuras económicas (Rodríguez, 2016). Es desde la citada perspectiva que se pretende analizar el funcionamiento de las medidas cautelares en el marco del activismo judicial. Al respecto, es importante hacer referencia al profesor Palomares (2015), para quien:

La implementación del sistema de precedente en Colombia implica no solo la resolución de cuestiones materiales, tales como la identidad del modelo jurídico colombiano o la reconfiguración del sistema de fuentes, sino también de cuestiones metodológicas, tales como la determinación de las técnicas de identificación, interpretación y aplicación de reglas de precedente. (Palomares, 2015, p. 29).

En concordancia con lo dispuesto, es importante resaltar:

que en los albores del neoconstitucionalismo, el derecho positivo quedó relegado al anacronismo que le impuso la puesta en práctica de los principios constitucionales. El Estado social de derecho, en el marco de la Constitución de 1991, va a encontrar en la exaltación de la dignidad de la persona humana el medio expedito para 
superar el rigorismo hermético de la ley, en procura de garantizar la realización de los contenidos axiológicos de la Carta. En este contexto se destaca la jurisprudencia de la Corte Constitucional de Colombia, corporación que logró traducir la forma monolítica de la ley a la diferente y compleja realidad social, consiguiendo que la irradiación de los principios constitucionales, y en concreto de la dignidad humana, se constituya en fundamento del intérprete y, de contera, en punto de referencia del ordenamiento jurídico. (Romero, 2011, p. 37).

De otro lado:

El cambio constitucional de 1991 en Colombia produjo una transformación en la comprensión y aplicación del derecho, el cual involucró a varios grupos que históricamente habían sido discriminados y que no eran vistos a nivel jurídico de forma diferencial, por lo que era improbable materializar sus derechos. Así, la igualdad adquiere una relevancia fundamental en el sistema constitucional, como principio se convirtió en eje dinamizador para la inclusión y como derecho en la posibilidad de amparo. (García, 2014, p. 15).

La presente disertación académica ha querido analizar de forma analítica y profunda el porqué de la importancia del tema de la cautela innominada, investigación de carácter cualitativo e investigativo, en la que las medidas cautelares innominadas son el tema central por desarrollar. Se esboza la necesidad que tiene la jurisdicción, para el caso que nos atañe de lo contencioso administrativo, de asegurarle a sus opuestos procesales que sus decisiones se podrán ejecutar sin que ello implique exceso de poder o extralimitación en las funciones del juez, convirtiéndose, a todas luces, en la principal garante en la ejecución de la sentencia.

Adicionalmente, es prudente destacar que la profundidad y el alcance del trabajo en mención fue posible gracias al desarrollo y a la identificación de la naturaleza jurídica tanto de las medidas cautelares innominadas como del activismo judicial, pasando a establecer tanto las fortalezas como los obstáculos de aquellas. El carácter restrictivo de esta medida le permite ser acogida de forma excepcional y le otorga al juez un poder especial en sí mismo; pero, por tratarse del carácter innominado, este poder se magnifica en razón de la ausencia de estipulación positiva, de manera que se resalta una necesidad que se hace imperiosa en el operador de justicia: la sana crítica a prima facie, la que ha permitido con ello el estudio de cómo el activismo 
judicial se ha consolidado en nuestra cultura jurídica llevando de la mano a esta figura innominada, la cual se ha encargado de darle certeza y eficacia al proceso. Es así como podemos afirmar categóricamente que las medidas cautelares innominadas fortalecen el activismo judicial en razón a que se encuentran plenamente demarcadas por unos límites legales establecidos por el legislador para tal efecto, obteniendo como resultado decisiones libres de toda arbitrariedad y vías de hecho, garantizando la tutela del derecho invocado.

\section{Naturaleza jurídica de las medidas cautelares innominadas}

La naturaleza de las medidas cautelares es la de asegurar las resultas del juicio, en prevención de un perjuicio irreparable en la definitiva del juicio, y son de cumplimiento obligatorio para el juez toda vez que se encuentren acreditados ambos supuestos de manera concurrente. (Ochoa, 2008).

Se da la necesidad de que la jurisdicción le asegure a las partes que sus decisiones se puedan ejecutar, siendo este uno de los elementos más valiosos de la tutela judicial efectiva y que excede el marco de las garantías procesales que se deducen del debido proceso, del derecho a la defensa y del acceso a la justicia, pues el legislador debe establecer instituciones con la posibilidad de que el juez pueda realmente ejecutar su sentencia. Una de las variables más importantes de las cuales depende la ejecución de la sentencia son las medidas cautelares. (Araújo-Oñate, 2011).

Para la Corte Constitucional, las medidas cautelares son aquellos instrumentos con los cuales el ordenamiento protege, de manera provisional y mientras dura el proceso, la integridad de un derecho que es controvertido en ese mismo proceso. De esa manera, el ordenamiento protege preventivamente a quien acude a las autoridades judiciales a reclamar un derecho, con el fin de garantizar que la decisión adoptada sea materialmente ejecutada. Por ello, esta corporación señaló, en casos anteriores, que estas medidas buscan asegurar el cumplimiento de la decisión que se adopte, porque los fallos serían ilusorios si la ley no estableciera mecanismos para asegurar sus resultados, impidiendo la destrucción o afectación del derecho controvertido. (Corte Constitucional, 2004).

Las medidas cautelares tienen amplio sustento constitucional, puesto que desarrollan el principio de eficacia de la administración de justicia, son un elemento 
integrante del derecho de todas las personas a acceder a la administración de justicia y contribuyen a la igualdad procesal. Sin embargo, la Corte Constitucional ha afirmado que, aunque el legislador goza de una considerable libertad para regular el tipo de instrumentos cautelares y su procedimiento de adopción, debe de todos modos obrar cuidadosamente por cuanto estas medidas, por su propia naturaleza, se imponen a una persona antes de que ella sea vencida en juicio. Por ende, los instrumentos cautelares, por su naturaleza preventiva, pueden llegar a afectar el derecho de defensa y el debido proceso, en la medida en que restringen un derecho de una persona antes de que ella sea condenada en un juicio. (Corte Constitucional, 2000).

La importancia de las medidas cautelares se da estrictamente en el campo judicial, por cuanto se procura con ellas garantizar el derecho pretendido por el actor y que su petición no resulte inocua.

Ahora bien, la medida cautelar procede previa y en el transcurso de la investigación procesal; tiene como fin esencial que no se vulneren los derechos de los intervinientes en la litis, garantizando compensar a la parte triunfante del proceso.

Ahora bien, la medida cautelar innominada tiene dos funciones:

1. Anticipar la garantía del cumplimiento del futuro fallo que se va a proferir.

2. La cautela innominada tiene como propósito en el curso del proceso ser el mecanismo para la protección del derecho que se discute en el proceso o para proteger a las personas que intervienen en ese proceso, impedir la infracción ante el derecho o evitar las consecuencias derivadas de la infracción ya cometida.

Es decir, las medidas cautelares innominadas son medidas garantizadoras de efectividad de la decisión judicial de fondo y están consagradas en nuestro ordenamiento jurídico en el "Código General del Proceso, en su artículo 590".

La medida cautelar innominada es aquella que no está prevista expresamente por el legislador, pero éste faculta al juez para que, en cada caso y mediante petición de parte, la decrete si la encuentra razonable para la protección del derecho objeto del litigio, impedir su infracción o evitar las consecuencias derivadas de esta, prevenir daños, hacer cesar los que se hubieren causado o asegurar la efectividad de la pretensión. (Letra c) del numeral 1 del artículo 590 del CGP).

El no contemplar la práctica de medidas cautelares en el proceso judicial sin duda haría nugatorio el derecho declarado o del que coercitivamente se exige su 
cumplimiento. De igual manera, la cautela practicada tiene el propósito de garantizar la no vulneración de los derechos de la parte o del tercero interviniente mientras transcurre el proceso, o bien, evitar su vulneración, lo primero a partir tanto de la cautela nominada como la innominada, lo segundo mediante la cautela innominada.

La Ley 1437 dedicó el capítulo XI para exponer un amplio espectro de medidas cautelares que con seguridad se constituyen en verdaderas herramientas para asegurar a los ciudadanos el acceso a la justicia y una efectiva tutela cautelar que garantizan el objeto del proceso, mientras se dicte sentencia. Hay que decir resueltamente que el mantenimiento del sistema estricto de la decisión previa no puede sostenerse más que al precio de un aumento sustancial del ámbito de las medidas cautelares a disposición del juez contencioso. Este sistema debe comprender toda la amplia gama de medidas conservatorias, pero también y sobre todo, de medidas cautelares de prestación positiva, que son perfectamente conocidas en el Derecho Anglosajón. (García de Enterría, 1991, p. 66).

Las nuevas medidas cautelares innominadas se encuentran en el el capítulo XI del Código de Procedimiento Administrativo y de lo Contencioso Administrativo, y la expectativa con ellas es conseguir que no haya más restricciones como las que se presentan por ahora. Para el efecto, la Doctrina ha considerado que para que exista una verdadera efectividad del acceso a la administración, es necesario contar con unas medidas cautelares que garanticen la efectividad de la sentencia (Parejo, 2016).

\section{La naturaleza jurídica del activismo judicial}

El término activismo judicial hace referencia a la práctica y concepción del juez como limitador de los demás poderes del Estado por medio de la aplicación de la Constitución y los derechos fundamentales. Reclama un mayor protagonismo de los tribunales y que las sentencias sean creadoras de derecho, con la intención de generar un cambio en la legislación, la jurisprudencia o la sociedad. Responde al fenómeno judicial manifestado de manera tanto internacional como nacional. (Activismo Judicial, 2016).

Para nuestro caso particular, varios tratadistas, entre otros Mauricio García, en su obra Emancipación social y violencia en Colombia, concuerdan en aseverar 
que el protagonismo judicial que adquiere la Corte Constitucional para fallar sus decisiones como progresista y dar el discernimiento de forjar un activismo judicial se da por varias razones (García, 1991).

Inicialmente, con nuestra Carta Política de 1991 se logró crear la Corte Constitucional para la protección de todos los ciudadanos, encauzando su atrevimiento a conseguir que esta desplegara su labor en desarrollar todos los medios posibles para obtener así la intervención de todos sus asociados y contribuir a velar por sus derechos. Pero lo pretendido no obtuvo los resultados esperados en virtud a la cantidad de falencias en la Constitución, por ello todos los asociados continuaron en la búsqueda de sus derechos por la vía judicial, pretendiendo con ello un fallo justo y a su favor.

Frente al fenómeno, el autor ya mencionado señala que los diseños de la justicia constitucional y la cultura jurídica posibilitan institucionalmente el activismo de la Corte Constitucional. Además, la crisis de representación y la debilidad de los movimientos sociales favorecen el recurso de los mecanismos jurídicos por parte de ciertos actores sociales. (García, 1991).

Cuando en el amplio campo del derecho procesal, los diferentes métodos de interpretación -tales como la doctrina, la ley, la jurisprudencia- establecen que entre las funciones principales del derecho procesal se encuentran inicialmente la regulación de la función jurisdiccional del Estado y seguidamente la manera para efectivizar el derecho sustancial, se observa la coalición del derecho sustancial con el derecho procesal.

Ahora bien, la llamada tutela judicial efectiva es el gran soporte dentro de cualquier proceso judicial, ya sea de carácter administrativo, civil, laboral, penal, entre otros, para garantizar el cumplimiento del fallo; es así, que podemos afirmar que cuando se solicita una medida cautelar y esta es decretada y practicada, el proceso toma un rumbo diferente.

Así las cosas, en el proceso de acción de inconstitucionalidad, la Corte Constitucional manifiesta lo siguiente:

A pesar que el legislador tiene la potestad de regular las cautelas y el procedimiento adoptado para las mismas, debe hacerlo de una forma cuidadosa. Precisamente por esa tensión es que la doctrina y los distintos ordenamientos jurídicos han 
establecido requisitos que deben ser cumplidos para que se pueda decretar una medida cautelar, con lo cual la ley busca que esos instrumentos cautelares sean razonables y proporcionados. (Corte Constitucional, 2000).

Igualmente, la Corte reitera que se debe cuidar la finalidad de la medida cautelar en el proceso de acción de inconstitucionalidad (Corte Constitucional, 2004, p. 1).

Es así como podemos concluir que el mandato constitucional garantizará el cumplimiento de las normas, los principios procesales y el acceso a la justicia, los principios de eficacia, celeridad, entre otros, que deben estar presentes en todo proceso judicial. Es evidente que el sistema judicial en nuestro país está cada día más congestionado, ya que los ciudadanos acuden frecuentemente con la finalidad de que al acudir a la justicia sea esta, ya sea por un medio de control o de una acción, la que conlleve una sentencia debidamente ejecutoria, la que declare la existencia de un derecho.

Lo importante no es solo tener acceso a la justicia, ya que, infortunadamente, en nuestro ordenamiento jurídico se evidencia la mora en los trámites judiciales, la justicia morosa y parsimoniosa; por ello surge la cautela innominada en el activismo judicial como solución transitoria y se encuentran los presupuestos de las medidas cautelares.

Como su nombre lo enuncia, los presupuestos de las medidas cautelares son la base para que el administrador de justicia; como la parte legitimada en el proceso, puedan ejercer la efectividad de un derecho con el "deber ser" de protegerlo, así se observa la necesidad de tales presupuestos por cuanto el sistema es extremadamente parsimonioso. Por esta razón surgen los presupuestos de las medidas cautelares que a continuación se indican:

\section{Fomus Boni Iuris (apariencia del buen derecho)}

Para decretar la medida cautelar, se debe partir de una apariencia del derecho o de un mínimo grado sobre la verosimilitud de este o, como indica alguna parte de la doctrina, que exista al menos un "humo" del derecho pretendido o invocado. Suposición en la situación jurídica planteada.

La cognición cautelar se limita, en todos los casos, a un juicio de probabilidades y de verosimilitud. Declarar la existencia del derecho es función de la providencia principal; en sede cautelar, basta que la existencia del derecho aparezca verosímil, 
esto es, basta que, según un cálculo de probabilidades, se pueda prever que la providencia principal declarará el derecho en sentido favorable a aquel que solicita la medida cautelar, por lo que el resultado de la cognición sumaria tiene el valor de una hipótesis. (Calamandrei, 1945).

Por otro lado, está Murillo (2007), quien afirma:

El perjuicio atendible por quien dispone la medida cautelar debe consistir en el riesgo de que se frustre la tutela efectiva que corresponde otorgar a la sentencia final. Ese riesgo y no otro. Lo cual obliga al juez que decide la medida cautelar a intentar una valoración prima facie de las respectivas posiciones, de forma que debe otorgar la tutela cautelar a quien tenga "apariencia de buen derecho" fumus boni iuris), precisamente para que la parte que sostiene una posición injusta manifiestamente no se beneficie, como es tan frecuente, con la larga duración del proceso y con la frustración, total o parcial, grande o pequeña, que de esa larga duración va a resultar para la otra parte como consecuencia del abuso procesal de su contrario. (Murillo, 2007, p. 2).

Siempre en todo asunto, ya sea administrativo o de cualquier otra jurisdicción, el juez, con las pruebas oportunamente allegadas al proceso, tomará su propio juicio de valor con el objeto de decretar la medida cautelar solicitada por medio de un trámite cautelar.

\section{Periculum In Mora (demora, tardanza por los trámites judiciales, peligro de la demora)}

Peligro en la demora (periculum in mora) significa que se dé la inseguridad en cuanto a que el derecho pretendido no se pueda consolidar debido a la tardanza en el proceso; es decir, el peligro en la demora en las actuaciones judiciales lleva a la ejecución de este presupuesto. Cabe resaltar que no es por la mora del funcionario, por el contrario, es por la mora en el trámite del proceso, en las actuaciones, por cuanto los procesos llevan una serie de etapas y términos, los cuales deben ser respetados no solo por el operador de justicia, sino también por las partes intervinientes en el conflicto. 


\section{Periculum In Damni (peligro de daño)}

Como su nombre lo indica, se define como el peligro de daño, es decir, por aquella desidia, tardanza, negligencia por parte del operador de justicia que, teniendo el deber jurídico de aplicar cada día los principios generales del derecho, como lo son la celeridad, la eficacia y la eficiencia, en todas y cada uno de sus actuaciones judiciales, no lo hace, lo cual conlleva un grave deterioro en el orden procedimental, lo que fácilmente implica un daño antijurídico en el tema administrativo o una eventual falla en el servicio judicial, ya que con esa tardanza por parte del servidor público se puede fácilmente acudir a otro medio de control y obtener una indemnización en forma legal.

\section{Contracautela}

Como un presupuesto más sin el cual no se decreta la medida cautelar, el fin principal de la contracautela es salvaguardar el porcentaje que el juez estime conveniente a la parte (tercero ajeno al conflicto) con la práctica de la cautela que pueda ver afectados sus intereses. Es el caso de advertir que el afectado tendrá su derecho al debido proceso al iniciar el respectivo incidente de desembargo dentro del término que legalmente corresponde.

\section{Principio de la razonabilidad y/o proporcionalidad}

Encontramos que la razonabilidad es sinónimo de proporcionalidad, ya que el operador judicial debe velar tanto por los derechos del demandante como por los del demandado, para evitar vulnerar los derechos de alguna de las partes. Esta proporcionalidad de la cautela no es un argumento nuevo, pues la doctrina ha venido pronunciándose con anterioridad.

Ahora bien, al respecto se tiene que:

[...] el juez, al controlar la decisión cautelar, deberá realizar un examen de proporcionalidad de la cautelar en sentido estricto. La medida debe ser proporcionada teniendo en cuenta los intereses en conflicto, los daños que pueda sufrir el demandante, los daños que pueda sufrir el demandado y los daños que puedan sufrir terceros. La medida cautelar proporcionada en sentido estricto no es más que la 
medida cautelar óptima. La respuesta será proporcionada cuando sus costes son inferiores a sus beneficios, y de una actuación desproporcionada cuando sus costes son muy superiores a los beneficios que se esperan de ella. (Veramendi, 2011).

\section{Fortalezas de las medidas cautelares innominadas en el activismo judicial}

Con la entrada en vigencia a nuestro ordenamiento jurídico del Código General del Proceso, se oberva cómo las cautelas innominadas se fortalecen en el activismo judicial. Con la inclusión del artículo 590 del Código General del Proceso, el legislador facultó al juez ampliamente en lo referente al procedimiento de las medidas cautelares; con ello, su poder decisorio sobre las cautelas aumentó y de esta manera la actividad judicial se fortaleció.

Es, sin lugar a dudas, el concepto de garantizar la efectividad de la pretensión bastante complejo para el juez a quien se le haga la proposición de su decreto, en razón a que puede incurrir en un prejuzgamiento del asunto, la limitación de derechos ciertos o la terminación anticipada del pleito por la concesión prematura de las peticiones queridas en la demanda; se trata, pues, de establecer que la medida cautelar innominada en este tema sea una herramienta que viabilice el aseguramiento. (Cabrera, 2014).

Es importante tener en cuenta que la facultad oficiosa otorgada al juez es una fortaleza en el activismo judicial y se constriñe solamente a que el operador judicial puede, en determinado momento, finalizar la cautela o cambiarla si lo considera conducente para el proceso, tomando en consideración que la medida cautelar debe ser a solicitud de la parte interesada para su decreto. Pero cabe advertir que el juez, al mirar la viabilidad sobre la solicitud y el decreto de la cautela, puede abstenerse de decretarla si observa que esta transgrede algún principio fundamental de los intervinientes dentro de la litis.

Por lo anterior, hay que tener en cuenta que la medida cautelar innominada solicitada no debe lesionar a ninguna de las partes en contienda, es por ello que el juez está en la obligación de tomar una decisión justa frente a esta solicitud, que redunde en la protección de los derechos fundamentales de las partes. 
La Corte Constitucional se ha pronunciado así al respecto:

Los instrumentos cautelares, por su naturaleza preventiva, pueden llegar a afectar el derecho de defensa y el debido proceso, en la medida en que restringen un derecho de una persona, antes de que ella sea condenada en un juicio. Existe pues una tensión entre la necesidad de que existan mecanismos cautelares que aseguren la efectividad de las decisiones judiciales y el hecho de que esos mecanismos pueden llegar a afectar el debido proceso, en la medida en que se imponen preventivamente, antes de que el demandado sea derrotado en el proceso. Precisamente por esa tensión es que la doctrina y los distintos ordenamientos jurídicos han establecido requisitos que deben ser cumplidos para que se pueda decretar una medida cautelar, con lo cual la ley busca que esos instrumentos cautelares sean razonables y proporcionados. (Corte Constitucional, 2013).

Aunado a lo anterior, Calamandrei (1945) define la potestad de la cautela así:

Aquel poder $[\ldots]$ confiado al juez fuera de los institutos singulares $[\ldots]$ y en virtud del cual el juez puede siempre, cuando se manifieste la posibilidad de un daño derivado del retardo de una providencia principal, proveer en vía preventiva a eliminar el peligro en la forma y con los medios que considere oportunos y apropiados al caso. (Calamandrei, 1945).

Igualmente, Redenti manifiesta:

La posibilidad de obtener providencias de carácter preventivo-cautelar, dejando en cada caso al juez no solo el valorar las razones de su oportunidad y urgencia, sino también el formar su contenido, como anticipo de lo que podrá después ser el posible o probable contenido de una futura providencia de fondo. (Redenti, 1957). Ortiz (2010) define esta potestad de la cautela así:

Una función otorgada a los órganos jurisdiccionales en el proceso mediante el cual las partes pueden pedir y el juez acordar, con relación al material fáctico subjudice, las medidas innominadas para evitar una situación de daño o de peligro o para evitar la continuidad de este, pudiendo las partes suplir el silencio de la ley en cuanto 
al contenido de la providencia y el juez evaluar la pertinencia o adecuación de estas (Ortiz, 2010).

Es por ello que cuando se le otorga al juez la posibilidad de legislar en cuanto a medidas cautelares innominadas, no se le brinda una capacidad discrecional amplia e ilimitada, sino, por el contrario, se le restringe frente a unos límites constitucionales y legales. Es claro que el operador judicial será quién tomará la decisión final sobre cuál medida cautelar aplicará a la litis y, por ello, la fortaleza de las medidas cautelares innominadas dentro del activismo judicial.

\section{Obstáculos de las medidas cautelares innominadas en el activismo judicial}

En relación con los posibles obstáculos de las medidas cautelares innominadas en el marco del activismo judicial, surge un interrogante respecto de la cautela innominada: ¿es la medida cautelar innominada un instrumento eficaz o una exuberante potestad facultativa otorgada al operador judicial?

Del tema nos ilustra González Camacho: "La medida cautelar solo tiene por objeto
el aseguramiento provisional de derechos o la pacificación provisoria, no puede
prejuzgar o anticipar la resolución de fondo. En efecto, no puede el juzgador, me-
diante una medida provisional, definir de manera anticipada el fondo del proceso
de una vez por todas, pues aparte del contradictorio imprescindible, se necesita
también de una amplia referencia probatoria que permita tomar una decisión con-
cienzuda y fundamentada sobre la materia en litigio. Está prohibido anticipar el re-
sultado del proceso principal por medio de una orden provisional, dicen los alema-
nes bajo el conocido dogma de la prohibición de anticipar la resolución de fondo".

Igualmente, el legislador, al crear un sistema cautelar que sea positivo, puede de esta manera facultar al juez para que este dicte las medidas cautelares que a bien estime pertinentes para el caso concreto, apareciendo entonces de este modo las medidas cautelares innominadas. Este fenómeno ha sido criticado cuando se señala que: 
Lo que el legislador realmente está haciendo es traspasar parte de su función legislativa al juez, ya que, en último término, será este quien determine las medidas cautelares. Sin embargo, hay que tener en cuenta que las realidades y los problemas van cambiando con el correr del tiempo, y de este modo, el legislador, al momento de ejercer su función legislativa, no puede tener en cuenta cada uno de los posibles problemas que se pueden llegar a generar y así darles una solución. Se ve claramente que es un instrumento a disposición del juez que lo que busca es la justicia, y es por esto que se debe tener gran cuidado en su implementación y establecer límites claros para que no se convierta en una decisión arbitraria y, con esto, injusta. (Ragone, 2015).

El poderío cautelar está conferido al juez, no por una regla específica, sino por el marco legal, porque el Estado demanda tutelar el derecho. El operador judicial, al decretar una medida cautelar, está regido de forma taxativa o innominada, esto con el ánimo de equilibrar las cargas de las partes en contienda, recordando el precepto legislativo de no sobrepasar los límites legales y constitucionales.

En Italia se discutió arduamente acerca del tipo de potestad cautelar que tenía su legislación. En efecto, la ley italiana se limitaba a enumerar las medidas cautelares, quedando en duda si estas se agotaban allí o si se debía reconocer al juez un poder cautelar general y, por ende, autorizarlo a dictar otras medidas cuando se manifieste la posibilidad de un daño derivado del retardo de la providencia principal. (Calamandrei, 1945).

Es decir, el daño a la contraparte por el retraso en el proceso debe solucionarse de forma legislativa, otorgándole poderes al juez para que disponga de un poder cautelar de forma innominada.

Pese a reconocer la utilidad práctica de la solución amplia, negaba la posibilidad de que existiera en su legislación la denominada potestad cautelar general, por faltar norma expresa del derecho positivo y, a mayor abundamiento, por no avenirse con los principios generales del derecho procesal de su país. (Salamanca, 2005). 
Este tratadista se negaba a aceptar el concepto de medida cautelar innominada por no encontrarse codificado y adicional, porque según él, atentaría contra los principios generales del derecho. Entonces serán la Constitución y la ley las que garantizarán que se enmarque dentro de sus límites la potestad cautelar del operador judicial.

\section{Conclusiones}

Es claro que la jurisdicción administrativa en Colombia se lleva todos los honores por tener los procesos más largos, en la que es latente el riesgo de que el objeto del litigio sufra modificaciones, perjudicando en últimas a las partes con la dilación de la sentencia definitiva. Debido a esto y por múltiples razones, la cautela innominada hoy por hoy se ha convertido en la precursora de la efectividad de la sentencia.

Cuando el Congreso nacional le otorga al togado la posibilidad de legislar en cuanto a las medidas cautelares innominadas, no le brinda una capacidad discrecional amplia e ilimitada, sino todo lo contrario, lo restringe frente a unos límites constitucionales y legales, so pena de desviar este poder e incurrir en arbitrariedades y vías de hecho. Es claro que será el operador judicial el que tomará la decisión sobre cuál de ellas, en la baraja de medidas cautelares, aplicará a la litis. Entonces, la medida en mención en sí misma no representa un obstáculo para el activismo judicial.

Teniendo en cuenta los presupuestos anteriores, resulta ser el activismo judicial el punto de quiebre en esta relación debido a que es en cabeza del juez, según su proactividad, que tal decisión es tomada de forma pronta, justa o es rechazada, es decir, que la toma de esta cautela redunda en salvaguardar los derechos fundamentales de las partes en contienda, vistos desde la perspectiva del interés general, sin dejar de lado que este deberá auspiciar el debido proceso, el acceso a la justicia y la igualdad, todo ello dentro de la sana crítica, llevada a su máxima expresión valorando con máximo detalle los elementos constitutivos de buen derecho.

Para concluir, no es esta disposición cautelar la que pudiera representar algún tipo de inseguridad jurídica, por el contrario, es el activismo judicial, en cabeza del operador judicial, el llamado a incurrir en algún tipo de error, escasa interpretación, falta de apreciación, vía de hecho, aunado a uno de los flagelos sociales más grandes en nuestro país, como lo es la corrupción, en síntesis, error humano.

Las fortalezas que las medidas cautelares innominadas representan frente al activismo judicial permiten respirar un aire de tranquilidad jurídica en virtud a 
que la facultad de legislar, otorgada por el Congreso al juez, podrá realizarla con la cláusula de que tales disposiciones deberán estar enmarcadas en la Constitución y la ley. También resulta importante el amplio margen de discrecionalidad conferido al operador judicial, en el que sus juicios de valor y su subjetividad le darán un sello particular al proceso. La medida adoptada por el legislador se justifica al encontrar que la sociedad, al igual que el derecho, se encuentra en constante evolución; y ante la imposibilidad de precisar todos los posibles hechos que involucra esta medida, prefirió dejar en manos del juez la decisión de adecuar la medida cautelar innominada al momento y a las condiciones sociales vigentes.

Otra de las particularidades de las cautelas en general es que solo proceden a solicitud de parte, es decir, son de carácter rogado; así las cosas, las medidas objeto de debate deberán basar sus pilares en la proporcionalidad y la razonabilidad, adecuadas y necesarias. Es por ello que resulta procedente afirmar que nos encontramos ante la precursora de la sentencia definitiva.

\section{Referencias}

Activismo Judicial. (mayo de 2016). Recuperado de https://es.wikipedia.org/wiki/ Activismo_judicial

Araújo-Oñate, R. M. (2011). Acceso a la justicia y tutela judicial efectiva. Propuesta para fortalecer la justicia administrativa. Visión de derecho comparado. Revista Estudios Socio-Jurídicos, 13(1), 247-291. Recuperado de goo.gl/zaiPi6

Asamblea Nacional Constituyente. (1991). Constitución Política de Colombia. Bogotá: Legis.

Cabrera, D. (2014). Estudio a las medidas cautelares innominadas, en vigencia del Código General del Proceso. Revista IUSTA, 1(40), 17-38. DOI: 10.15332/ s1900-0448.2014.0040.06

Calamandrei, P. (1945). Introducción al estudio sistemático de las providencias cautelares. Buenos Aires: Editorial Gráfica Argentina.

Código General del Proceso (12 de 07 de 2012).

Corte Constitucional. (2000). Sentencia C-490/00. M. P. Alejandro Martínez Caballero.

Corte Constitucional. (2004). Sentencia C-379/04. M. P. Alfredo Beltrán Sierra.

Corte Constitucional. (2003). Sentencia C-485/2003. M. S. Marco Gerardo Monroy.

Corte Constitucional. (2013). Sentencia C-835/13. M. P. Nilson Pinilla Pinilla.

Fábrega, J. y Arjona, A. A. (1989). Medidas cautelares innominadas. Revista del Instituto Colombiano de Derecho Procesal, 8(8), 113-120. Recuperado de goo.gl/SkhFwt 
Feoli Villalobos, M. (2015). El nuevo protagonismo de los jueces: una propuesta para el análisis del activismo judicial. Revista de Derecho-Universidad Católica del Norte, 22(2), 173-198. DOI: 10.4067/S0718-97532015000200006

García, M. A. (13 de marzo de 2014). Medidas cautelares innominadas. La República. Recuperado de goo.gl/r8JYf5

De Sousa Santos, B. y García Villegas, M. (2004). Emancipación social y violencia en Colombia. Bogotá: Grupo Editorial Norma.

García de Enterría, E. (1991). Nuevas medidas cautelares “positivas”: La imposición por vía cautelar a la administración de la obligación de continuar un procedimiento eliminando un obstáculo inicial sin apariencia de buen derecho. (Auto de la Sala de lo ContenciosoAdministrativo del Tribunal Superior de Justicia del País Vsco, de 14 de octubre de 1991). (Comentarios Monográficos). Revista de Administración Pública, 126, $297-307$. Recuperado de goo.gl/ApCjWM

García, L. (2014). Elementos emancipatorios en la educación legal para jueces a partir de la Constitución de 1991. Revista Verba Iuris, 32, 15-32. Recuperado de goo.g1/4hfoFP Jinesta Lobo, E. (1996). La tutela Cautelar atípica en el Proceso Contencioso-Administrativo (1. ed.). San José, Costa Rica: Colegio de Abogados de Costa Rica.

JL Legado Jurídico. (5 de junio de 2010). Medidas innominadas [Mensaje en un blog]. Recuperado de goo.g1/Cv4IO4

Maraniello, P.A. (2012). El activismo judicial, una herramienta de protección constitucional. Revista TLA-MELAUA, 32, 46-83. Recuperado de goo.g1/mefltr Marín, J. C. (2006). Las medidas cautelares en el ordenamiento jurídico chileno: su tratamiento en algunas leyes especiales. Revista Estudios de la Justicia, 8, 13-37. DOI: 10.5354/0718-4735.2006.15100

Murillo, K. M. (2007). Generalidades sobre las medidas cautelares en el ámbito jurídico. En Nuevas tendencias de las medidas cautelares en la Jurisdicción Contencioso-Administrativa. Análisis de la jurisprudencia judicial en los últimos diez años (1995-2005) (Tesis de licenciatura, Universidad de Costa Rica, San José, Costa Rica) (pp. 9-100). Recuperada de goo.g1/NSSrfR

Ochoa, G. F. (11 de mayo de 2008). Naturaleza de las medidas cautelares [Mensaje en un blog]. Recuperado de goo.g1/OyXLRG Ortiz Ortiz Rafael (2010), El poder cautelar indeterminado y las medidas cautelares objetivas

Palomares, J. (2015). El carácter vinculante de la jurisprudencia constitucional en el derecho alemán. Revista Via Inveniendi et Iudicandi, 10(2), 29-56. Recuperado de goo.g1/JA6YiE

Parejo, L. A. (2016 [1983]). Lecciones de derecho administrativo (8. ${ }^{a}$ ed. revisada y actualizada). Valencia: Tirant lo Blanch. 
Ragone, Á. J. (2015). De la tutela cautelar innominada y la potestad discrecional del juez. Revista de Derecho Procesal Contemporáneo, 1, 67-82. Recuperado de goo.gl/Us $U_{z} I S$

Redenti. E. (1957). Derecho procesal civil (Tomo II). Buenos Aires: Ediciones Jurídicas Europeas.

Restrepo, M. A. (2005). La necesidad de ampliar la tutela cautelar judicial en el proceso contencioso administrativo. Estudios Socio-Jurídicos, 7(2), 191-205. Recuperado de goo. $\mathrm{g} 1 /$ mwujyP

Rodríguez, E. (2016). El pasaje del Estado y el derecho a la postmodernidad en Revista Via InveniendI et Iudicandi, 11(2), 11-37. Recuperado de goo.gl/WzV19q

Romero, J. P. (2011). Caleidoscopio del principio de la dignidad humana desde la jurisprudencia constitucional colombiana. Revista IUSTA, 1(34), 37-62. DOI: 10.15332/ s1900-0448.2011.0034.02

Salamanca, B. (2005). Las medidas cautelares innominadas en el proceso civil. Recuperado de goo.gl/OJZUXR

Santaella, C. (s. f.). Las medidas innominadas. Recuperado de goo.gl/xhj58h

Urdaneta, C. A. (2004). Introducción al análisis sistemático de las medidas cautelares atípicas del Código de Procedimiento Civil Venezolano. Revista de Derecho, 59. Recuperado de goo.g1/eqwsZM

Veramendi Flores, E. (20 de septiembre de 2011). El nuevo presupuesto de la medida cautelar: la razonabilidad. Boletín Virtual Facultad de Derecho UPSJB. Recuperado de goo.gl/x4z5ZY 